\title{
Preschoolers' Trust in Social Consensus Varies by Context: Conventional vs. Moral Domains
}

\author{
Silvia Guerrero ${ }^{1, *}$, Laura Elenbaas ${ }^{2}$, Ileana Enesco ${ }^{3}$, and Melanie Killen ${ }^{2}$ \\ 1 Universidad de Castilla-La Mancha (Spain). \\ 2 University of Maryland (USA). \\ 3 Universidad Complutense de Madrid (Spain).
}

\begin{abstract}
Título: La confianza de los niños en el consenso depende del contexto: convencional vs. moral.

Resumen: Cuando una mayoría aprueba una exclusión social ¿los niños son fieles a sus opiniones personales o muestran deferencia hacia la mayoría? Teniendo en cuenta investigaciones previas sobre la preferencia de los niños por el testimonio de una mayoría de adultos frente al de un disidente cuando deben aprender palabras, en este trabajo se estudió esta preferencia por el consenso social en dos contextos: exclusión racial entre iguales y aprendizaje de palabras nuevas. El objetivo fue estudiar si la preferencia por la mayoría puede generalizarse a otros contextos. En este trabajo participaron 90 niños de Educación Infantil del grupo étnico mayoritario en España. Los resultados mostraron que los niños se alineaban con la mayoría significativamente menos en el contexto de exclusión que en el de aprendizaje de palabras. Además, rechazaban la opinión del consenso cuando este aprobaba la exclusión de un niño de una actividad grupal, incluso cuando el excluido era de un grupo étnico-racial diferente al propio; por el contrario, los participantes se alineaban con el disidente que condenaba la exclusión, a pesar de que esto implicaba oponerse a la mayoría. Estos resultados proporcionan información relevante sobre el desarrollo del conocimiento social infantil.
\end{abstract}

Palabras clave: desarrollo social; desarrollo cognitivo; juicios morales; consenso social; testimonio.

\section{Introduction}

Cognitive developmental theories emphasize the role of the child in constructing his/her own knowledge through interaction and experience with the world and with other people (Gopnik \& Wellman, 2012; Piaget, 1932, 1954). Yet, not all information can be learned first-hand, making the information provided by others an important source of knowledge. Recently, developmental researchers have proposed that others' testimony is relevant as children learn and reason about the physical, natural, and social world. Recent studies have shown that children make use of direct information from others when they acquire conventional knowledge in many social contexts (Harris, 2012; Jaswal, 2010; Jaswal, Carrington, Setia, \& Cole, 2010).

One of the variables explored in previous research on individuals' use of others' testimony is the influence of consensus. That is, previous research has investigated how individuals respond when most of the people in a group say the same thing or hold the same view. The influence of consensus testimony on adults' learning, decisions, and behavior has been studied extensively since Asch's (1956) seminal work on conformity (Bond \& Smith, 1996). Although studies with chil-

* Correspondence address [Dirección para correspondencia]

Silvia Guerrero, Facultad de Educación. Universidad de Castilla-La

Mancha. Campus Fábrica de Armas. Avda. Carlos III, s/n. 45071. Toledo (Spain). E-mail: silvia.guerrero@uclm.es
Abstract: Do young children give priority to following personal beliefs over the testimony of a majority group of adults that approves of social exclusion? Following current research on children's preference for nondissenters when learning the names for novel objects, this study investigated children's preference for consensus opinion in two contexts: Interracial social exclusion among peers and novel object labeling. The goal was to examine the generalizability of preference for the opinion of nondissenters in a socially relevant context. This study was conducted with 90 preschool children from the Spanish ethnic majority group. The findings revealed that participants sided with the consensus significantly less often in the social exclusion context than in the novel object labeling context. Moreover, young children did not defer to the opinion of a numerical consensus in the socially meaningful context when a group condoned the exclusion of a peer from a group activity, even when the peer was from an outgroup social category. Instead, participants agreed with a dissenter who claimed that it was not okay to exclude someone, despite the opposite opinion of a numerical majority. These results provide new information regarding children's social knowledge development.

Key words: social development; cognitive development; moral judgments; social consensus; testimony.

dren are far less numerous than studies with adult participants, recent research has shown that young children, too, respond to consensus testimony. For example, young children rely on information from three adults in consensus rather than a lone dissenting adult regarding the correct name for a novel object (Chen, Corriveau, \& Harris, 2013; Corriveau, Fusaro, \& Harris, 2009; Fusaro \& Harris, 2008). Likewise, related work on other conventional norms like forms of greeting, modes of dress, or classroom rules, has revealed that young children draw on social consensus when evaluating these rules, the reasons for them, and the consequences of violating such conventional norms (see Smetana, Jambon, \& Ball, 2014, for a review).

Children also hear consensus testimony about issues that are not conventional in nature, however, and their use of group agreement to make decisions in these contexts is less well understood. For example, while social conventions --or conventional norms-- are evaluated as legitimate on the basis of consensus and authority mandates, norms pertaining to others' welfare, fairness, and just treatment are viewed as resulting not from consensus or authority but from an evaluation of the intrinsic nature of an act, and the consequences to a victim (Nucci, 2001, 2002; Turiel, 1983, 1998). Research on moral judgment has shown that, by four years of age, children use different criteria and reasoning to evaluate conventional and moral norms (Killen \& Smetana, 2015; Nucci, 2001; Turiel, 1983, 2002). Children view moral transgressions as wrong even when an adult or a consensus group condones 
them, and view moral rules as unalterable regardless of group opinion (e.g., if a school decides to change the rule that "hitting is wrong" children still deem it to be "not okay").

Many social interactions in young children's lives require coordination of conventional knowledge about traditions and expectations with moral norms about the fair treatment of others. For example, social exclusion from groups is an extremely salient aspect of social life for young children. Although preschoolers independently reason that exclusion based solely on gender or race is unfair by moral standards, such actions are sometimes deemed justifiable on the basis of conventional concerns about "fitting in" (Killen \& Rutland, 2011; Rutland \& Killen, 2015). As one illustration, preschool aged children viewed it as unfair for a group of girls to exclude a boy from playing with dolls, or for a group of boys to exclude a girl from playing with trucks, even though most children recognize and condone gender-segregated activities (Theimer, Killen, \& Stangor, 2001). If there is only room for one child to play, however, young children often choose the gender-stereotypic peer (i.e., a girl to play with dolls or a boy to play with trucks), and reason about who is likely to fit in best with the group and activity (Theimer et al., 2001). Thus, instances of social exclusion invoke both moral issues of fairness and others' welfare as well as conventional issues of customs and expectations for children.

Given that children consider both conventional norms and moral norms when making decisions in social contexts, the first aim of this project was to test the contextual specificity of children's use of consensus opinion. To achieve this, children's reliance on consensus testimony was tested in two contexts, one related to the fair treatment of peers in an interracial social exclusion context (socially relevant context) and one related to novel object labeling. The second context was based on that explored in previous work on children's use of consensus testimony (Chen, Corriveau, \& Harris, 2011; Chen et al. 2013). The first context drew on research examining children's moral reasoning regarding intergroup social exclusion (Killen \& Rutland, 2011). For both contexts, we measured children's judgments and reasoning when the opinions of a group consensus and one dissenter contrasted.

We propose that children's use of consensus testimony is contextual (not domain-general), and comprises one of many sources of information that children use to form judgments and make decisions. As well, children bring their own cognitive and social-cognitive interpretations of events in the world to bear on their judgments in social contexts. Accordingly, we hypothesized that, due to the different nature of each context, children would be more likely to side with the consensus in the conventional labeling context than in the social exclusion context. Specifically, the social exclusion context involved making a judgment about an act with negative intrinsic consequences to another person, which has been shown to be resilient to authority mandates in previous research (Smetana, 1985). Based on previous studies on children's moral judgments about social exclusion, we predicted that in the peer exclusion context, in which the group con- sensus approved of the exclusion while the dissenter disapproved of it, children would side with the dissenter (who said that exclusion was wrong or "not okay"). Thus, children would give priority to following personal moral beliefs over the testimony of others who approve of social exclusion. Regarding the object labeling (conventional) context, we predicted that preschoolers would defer to the opinion of the consensus, as has been shown in previous work (Chen et al., 2011; 2013).

An additional novel dimension of the present research involved measuring young children's reasoning for their decisions in both the object labeling and evaluation of peer social exclusion contexts (i.e., why they agreed with the opinion of either the consensus or the dissenter). It has recently been suggested that the importance of whether children understand their informants' reasons for giving testimony has been underestimated (Koenig, 2012), and children's reasons for trusting in or doubting their informants should be further explored (Mills, 2013). Extensive research on children's moral development indicates that children as young as 3 years of age reason about why behavior is acceptable or unacceptable from a moral viewpoint with references to fairness, equality, and empathy (see Smetana, et al., 2014, for a review), and some previous research on children's trust in testimony suggests that young children can reason about informant accuracy (Einav \& Robinson, 2010; Fitneva \& Dunfield, 2010; Koenig \& Harris, 2005). However, because no studies on children's use of testimony in object labeling contexts have systematically examined young children's reasons for their decisions, expectations for this context were limited to the presence or absence of verbal justifications related to the opinion of the group consensus.

For the object labeling context, we predicted that, if children sided with the consensus, they would reference the presence of a group consensus; otherwise they would justify their elections with reference to their own ideas. In contrast, previous work on young children's evaluations of social exclusion allowed for more detailed hypotheses for this context. We used the framework of social domain theory, which identifies three domains (moral, societal, and psychological) as central to social evaluations of complex events including interracial social exclusion (Turiel, 2002). When asked for their explanations for their decisions, we predicted that, in the social exclusion context, preschoolers would reference their perceptions of social exclusion as morally wrong, using reasons pertaining to unfairness and harm to others. Because children were not provided with other contextual information about exclusion other than the race of the excluded target, we expected a predominant use of moral justifications, rather than a range of moral, conventional, and personal choice reasons which would be expected in multifaceted social exclusion contexts.

Additionally, this study expanded on recent research assessing the impact of informant racial group membership on children's use of others' testimony by varying the race of the dissenter (Black, White) and holding constant the race of the 
consensus group (White). Thus, in addition to our hypotheses about the influence of a numerical social consensus in object labeling and interracial social exclusions contexts, this study also explored the relevance of racial/ethnic group membership of the informants on young children's decisions in both contexts. Research on racial/ethnic group identification in young children has found that, from 3-4 years of age, children in racial/ethnic majority groups typically express a same-race (or "ingroup") preference, and implicit bias towards individuals from other groups ("outgroups") usually appears around 6 years of age as children gain knowledge about racial/ethnic stereotypes (Dunham, Baron, \& Banaji, 2006; Enesco, Lago, Rodríguez, \& Guerrero, 2011; Rutland, Cameron, Bennett, \& Ferrell; 2005).

However, when other social factors are present, such as issues of unfairness, children do not consistently make decisions based on ingroup bias (Killen \& Stangor, 2001). Young children often give priority to fairness or equality (for a general review of the development of prejudice see Levy \& Killen, 2008; Guerrero, Enesco \& Pons, 2011). Thus, examining the role of consensus in intergroup contexts regarding issues such as social exclusion is warranted. Related work has found that children prefer to learn new names for objects and the functions of new objects from people from their own linguistic or racial/ethnic group rather than from people from other groups (Kinzler, Corriveau, \& Harris, 2011; Shutts, Banaji, \& Spelke, 2010). These results have been interpreted in terms of young children's ingroup bias (or preference for members of their ingroup over members of outgroups). However, race/ethnicity is not always a salient variable when a numerical consensus is present (e.g.: Chen, et al., 2011 for object labeling/word learning). In the current study, the race of the numerical consensus was held constant (ingroup: White), and the race of the single dissenter was varied (ingroup, outgroup). To simplify the design, all participants were White (the racial/ethnic majority group).

We predicted that in the social exclusion context, children would agree with the dissenter (who advocated a nonprejudiced behavior) rather than the group consensus (who advocated a prejudiced behavior) regardless of the race of their informants, given previous findings with older children who viewed racial exclusion as unfair and were willing to challenge peers who supported racial exclusion (Killen \& Stangor, 2001). While previous studies on object labeling have found that consensus preference is more pronounced when the race of the consensus group matches that of the child (Chen, et al., 2011, 2013), we did not make a specific prediction about the role of the race of dissenter in this context given that we did not have a specific prediction regarding children's decisions in the context of object labeling.

\section{Method}

\section{Participants}

Participants were 90 preschool children $\left(M_{\text {age }}=57\right.$ months, age range: $45-71$ months, 45 females) from the Spanish ethnic majority group. Children were recruited from public and semi-private schools. The socioeconomic level of the participants was not individually measured, but we selected schools situated in residential areas of average socioeconomic level in Madrid, Burgos, and Toledo, Spain. Written parental consent, as well as children's verbal assent, was obtained for all participants.

\section{Materials and Procedure}

Participants viewed photographs featuring a three-person consensus and a dissenter, and were asked with whom they agreed in two different contexts: 1) interracial social exclusion, and 2) novel object labeling (see Figure 1).

All informants were young, female, had similar body types, presented neutral facial expressions, and were photographed wearing white T-shirts and blue jeans with loose hair away from their faces. The four informants were shown in a photo, in which one individual (the dissenter) stood a few feet away from the other three individuals (the consensus group). In each photo, three women (the consensus) stood together with one of their arms down, pointing at one of the two stimuli (an object in the object labeling context or a smiling/sad face in the social exclusion context) and the woman alone (the dissenter) stood pointing at the opposite stimuli.

Conditions (race of dissenter). Participants were randomly assigned to one of two conditions. In the same-race condition, three White informants formed the group consensus. The dissenter was also White. In the different-race condition, three White informants formed the group consensus. The dissenter was Black. The location of the dissenter (to the left or to the right of the group consensus) varied systematically across participants, in order to avoid side bias or any pattern of response based on the position of informants.

Interracial social exclusion context. Participants completed two trials. Children were asked about their evaluations of instances of interracial social exclusion ("okay" or "not okay") when a group consensus shared their opinion that such exclusion was "okay" and one dissenter shared her opinion that it was "not okay".

$\mathrm{n}$ the first trial, participants viewed a drawing depicting three White children at a birthday party, and a Black child sitting outside the house looking inside. The race of the children depicted in the cartoons was never mentioned. The experimenter said: "Look what happened here. Ana [experimenter points to one of the characters presented in the drawing] has invited some kids to her birthday party but she didn't invite Rosa [experimenter points to the excluded girl]. And we asked these girls about what Ana did. These girls 


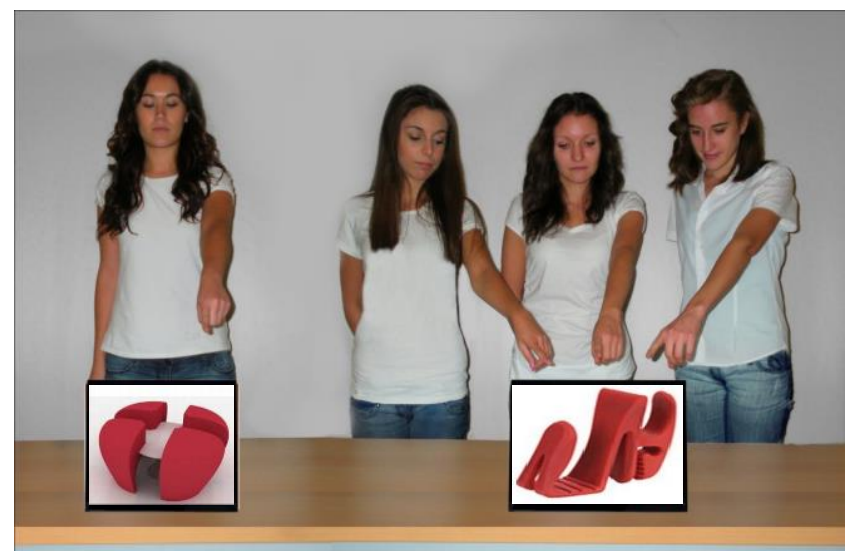

(1)
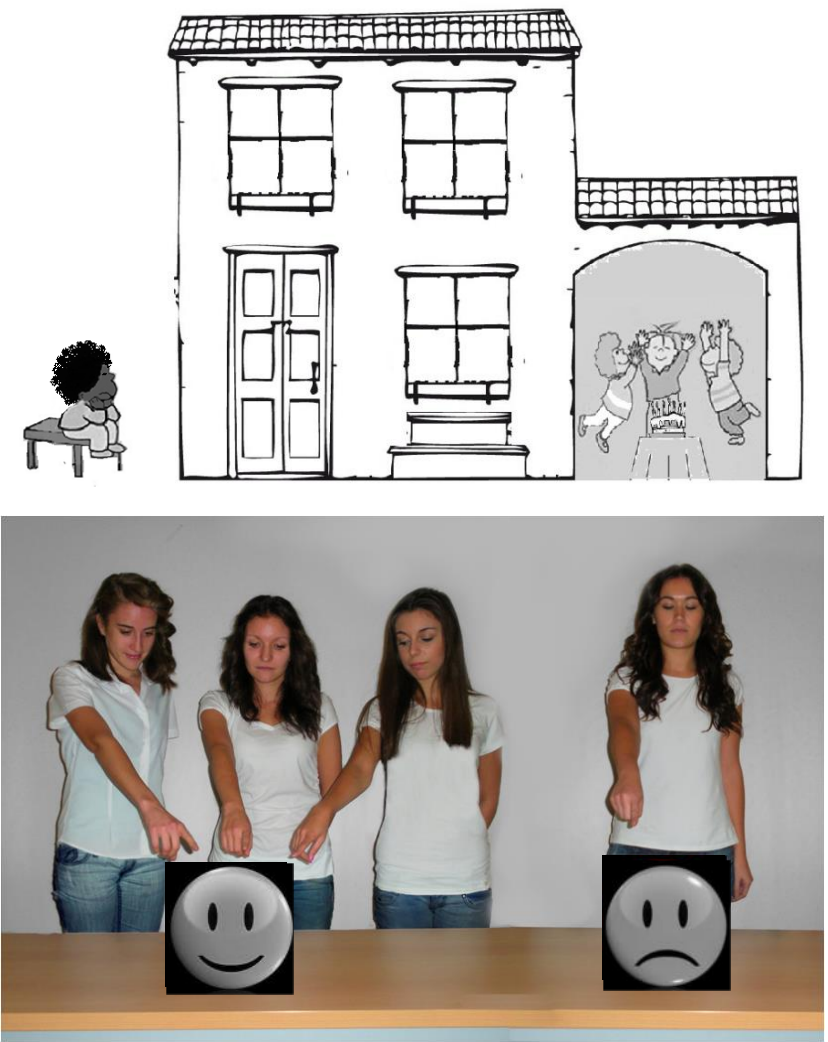

(2)

Figure 1. Example of stimuli shown to children on a computer screen, regarding the labeling context (1) and the social exclusion context (2).

said that it was okay [experimenter points to the consensus formation and the happy face]; and this girl said that it was not okay [experimenter points to the dissenter and the sad face]. So, what do you think? Is it okay or not okay that Ana didn't invite Rosa to her birthday party? You think it was okay/not okay that she did that. Why do you think it was okay/not okay that Ana didn't invite Rosa to her birthday party?" In this context, the informants from the group con- sensus pointed at a smiling face (indicating it is okay to not invite Rosa') and the dissenter pointed at a sad face (indicating 'it is not okay to not invite Rosa').

In the second trial for this context, participants viewed a drawing depicting three White children playing on a playground on the monkey bars. A Black child was sitting on the side, looking at the group but not playing with anyone. The experimenter said: "Look what happened here. Clara [experimenter points to one of the characters presented in the drawing] is playing on the monkey bars with her friends, but she didn't let María join them [experimenter points to the excluded girl]. And we asked these girls about what Clara did. These girls said that it was okay [experimenter points to the consensus formation and the happy face]; and this girl said that it was not okay [experimenter points to the dissenter and the sad face]. So, what do you think? Is it okay or not okay that Clara didn't let María play with them on the monkey bars? You think it was okay/not okay that she did that. Why do you think it was okay/not okay that Clara didn't let María play with them on the monkey bars?" Again, the informants from the group consensus pointed to a smiling face ('okay') and the dissenter pointed to a sad face ('not okay'). The characters and names used in the stories matched the gender of the participant. In both trials participants made their decisions with the photographs of the informants in plain sight.

Novel object labeling context. Participants completed two trials. In the first trial, participants viewed two photographs, each featuring four female informants and two novel objects positioned on a table in front of them. The experimenter said: "We have asked these girls which one of these is a Reso, and here's what they said. These girls said that this is a Reso [experimenter points to the consensus formation and object A] and this girl said that this is a Reso [experimenter points to the dissenter and object B]. So, which one do you think is the Reso? And, why do you think that's the Reso?" The same procedure was conducted for the second trial (Teno). Both Reso and Teno are pseudo (made up) words. In both trials, participants made their decisions with the photographs of the informants in plain sight.

Presentation order. Participants were randomly assigned to one of two orders of stimulus presentation. In Order 1, children completed the first novel object labeling scenario trial (Reso), followed by the first social exclusion scenario trial (Birthday Party), followed by the second novel object labeling scenario trial (Teno) and concluding with the second social exclusion scenario trial (Monkey Bars). In Order 2, children started with the first social exclusion scenario trial (Birthday Party), followed by the first novel object labeling scenario trial (Reso), followed by the second social exclusion scenario trial (Monkey Bars) and concluding with the second novel object labeling scenario trial (Teno). 


\section{Response Coding and Reliability}

Judgments. Participants' dichotomous responses across trials within the same context (i.e., across both social exclusion trials and both novel object labeling trials) were compared using McNemar tests. No significant differences were found between agreement with the group consensus in Trial One and Trial Two within-context (for social exclusion: Birthday Party, Monkey Bars; and for novel object labeling: Reso, Teno). Thus, for all analyses, participants' dichotomous responses to the two trials were scored on a 2-point scale within context: score $=0$ when participants agreed with the dissenter twice; score $=1$ when participants agreed once with the dissenter and once with the consensus; and score $=2$ when participants agreed with the consensus twice.

Justifications. Participants' open-ended justifications for their decisions in the interracial social exclusion context ("Why do you think it's okay/not okay that X didn't invite $\mathrm{Y}$ to his/her birthday party/that $\mathrm{X}$ didn't let $\mathrm{Y}$ play with them on the monkey bars?") were coded into four categories for analyses. Content categories were based on previous studies on social exclusion drawing on social domain theory (Killen \& Rutland, 2011). The categories were: 1) Fairness and sharing (e.g., "It's not fair that he didn't get to play", "Everyone is entitled to play", "It's not fair that he didn't invite him"), 2) Empathy (e.g., "Then she might cry", "He would be bored and sad"), 3) Punishment, authority and conventions (e.g., "Because your mom says that you must invite Rosa"), and 4) undifferentiated or circular responses with no additional reasons (e.g., "I don't know", "Because she was not invited"). No participants mentioned the opinion or testimony of the consensus as a criterion for their decision in the evaluation of social exclusion context, and no participants referenced the race of the dissenter when justifying their decision in either context. Only one (out of the 90 participants) gave justifications from two different content categories (e.g., fairness and empathy), and in this case only the first response was coded.

For the novel object labeling task ("Why do you think that's the Reso/Teno?") participants' justifications were coded into three content categories: 1) Physical/visible attributes of the object (e.g., "It is red", "It has a circle"), 2) Influence of the consensus (e.g., "There are more people pointing at it"), and 3) undifferentiated or circular responses with no additional reasons (e.g., "I don't know", "Because it is a Reso").
The coding of all justifications was conducted by two coders blind to the hypotheses of the study. On the basis of $25 \%$ of the interviews ( $n=23$ data points), inter-rater reliability was calculated at Cohen's $K=.89$.

\section{Results}

\section{Agreement Decisions}

Preliminary tests for differences in children's responses by gender (boy, girl) and by order of task presentation (Order 1, Order 2, as above) were performed. No significant differences were found in any of the comparisons. Consequently, gender and presentation order were pooled in all analyses.

A 2 (Race of Dissenter: White, Black) X 2 (Context: Novel Object Labeling, Social Exclusion Evaluation) ANOVA was conducted with repeated measures on the last factor. A main effect was found for context, $F(1,88)=117.24, p<$ $.001, \eta_{p}^{2}=.57$, revealing that participants sided with the consensus significantly less often in the social exclusion evaluation context $(M=.08, S D=.34)$ than in the novel object labeling context $(M=1.09, S D=.80)$. No other effects (for race of dissenter) were significant.

Additional tests were conducted in order to compare children's responses in the social exclusion evaluation and novel object labeling contexts against chance, which was calculated to be a score of 1 out of a possible total of 2 (for each context). Participants displayed a systematic opposition to the testimony of the majority in the evaluation of social exclusion context (it is okay to not invite $X$ ), siding with the dissenter who said it was "not okay" on average at a rate that significantly exceeded what would be expected by chance, $t(89)=-25.53, p=.001,(M=.08, S D=.34)$. Across both scenarios (Birthday Party, Monkey Bars), only $3.3 \%$ of participants $(n=3)$ agreed with the consensus once and only $2.2 \%(\mathrm{n}=2)$ agreed twice; the rest of the participants ( $\mathrm{n}=$ $85,94.4 \%)$ never agreed with the consensus in this context (see Figure 2).

In the novel object labeling context, participants' preference for the testimony of the consensus versus the dissenter did not differ significantly from chance, $t(89)=1.05, p=.30$, $(M=1.09, S D=.80)$. Across both scenarios (Reso, Teno), $36.7 \%$ of participants $(\mathrm{n}=33)$ agreed with the consensus twice, $35.6 \%(n=32)$ agreed once, and $27.8 \%(n=22)$ never agreed with the consensus (see Figure 2). 


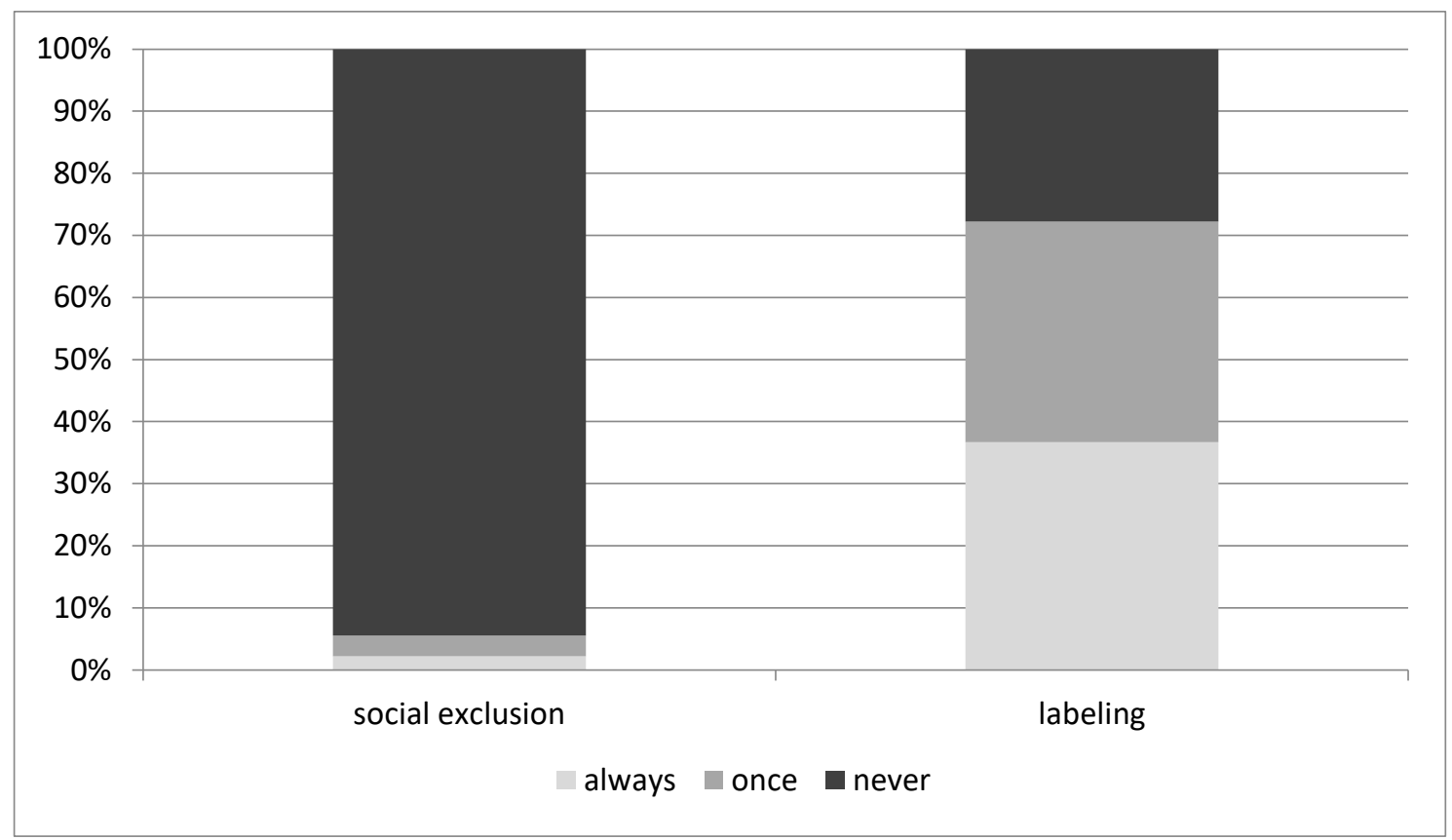

Figure 2. Percentage of children siding with the majority always, once or never, by context.

Our hypotheses for the evaluation of social exclusion context were supported: Children did not automatically side with the opinion of the consensus. Instead, they were against the majority, agreeing with the dissenter's testimony that social exclusion was not acceptable, and this decision did not vary by the race of the informants. Our findings for the novel object labeling context revealed that children did not prefer consensus testimony, instead they were equally likely to agree with the dissenter as with the consensus in this context, and did so regardless of the race of the informants.

\section{Justifications for Decisions}

In the social exclusion context, where the vast majority of children sided with the dissenter's claim that social exclusion was "not okay", over $50 \%$ of codable justifications referenced fairness or empathy for the excluded child. In the novel object labeling context, the majority of children's justifications were related to physical attributes of the object (e.g., color, shape) regardless of whether they had sided with the consensus (61.2\% "physical attributes") or the dissenter (68.3\% "physical attributes") testimony. Among the children who sided with the consensus, $14.3 \%$ justified their decision with reference to the group consensus.

Table 1 displays children's explanations for their decisions in both contexts, split by whether they agreed with the consensus or the dissenter. Because children were asked to explain their decision in each trial, the number of responses in these tables is greater than the number of participants for each context. Several children were unable to give any justification; $28.1 \%$ in the novel object labeling context and $40.7 \%$ in the evaluation of peer social exclusion context; but the rest of the sample gave some reason for their election.

Table 1. Number of Justifications for Decisions to Side with the Consensus or the Dissenter by Context (Percentages in Parentheses).

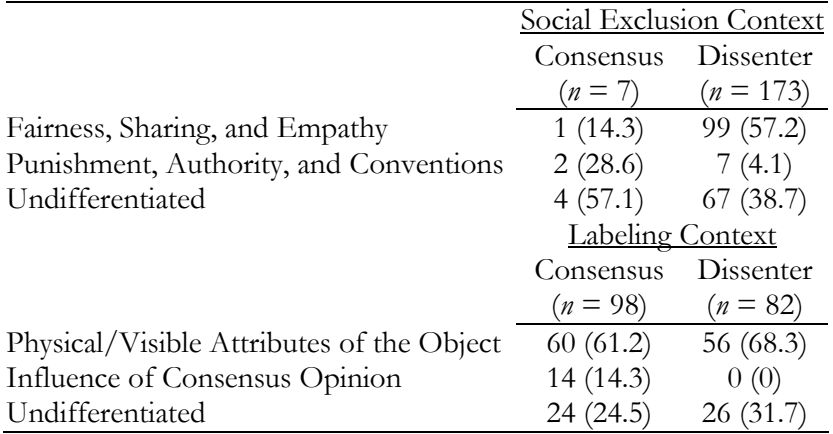

Our hypotheses regarding children's justifications for their decisions were confirmed. In the evaluation of social exclusion context, children explained their decisions with reference to their perceptions of interracial social exclusion as unfair and harmful. In the novel object labeling context, children rarely referenced the consensus testimony; instead they cited characteristics of the object as the basis for their decision. This latter finding supports research in child language acquisition, which argues that children construct language via reciprocal interactions rather than passively accepting all vocabulary-related testimony from others (Slobin, 2001). 


\section{Discussion}

This study was novel in its examination of the role of consensus testimony in young children's decisions in a morallyrelevant context, and in its assessment of children's reasons for their decisions after hearing consensus testimony. We found that young children were selective in how they used information provided by others, siding with the consensus more often in the novel object labeling context then in the social exclusion context. This means that children's preference for consensus testimony did not generalize across all social contexts. Instead, when a majority advocated for exclusion, children agreed with the testimony of a single dissenter who stated that peer social exclusion was unacceptable. When evaluating this morally salient social context, participants' justifications revealed that they were focused on the implications for the excluded child rather than on the opinion of the social consensus group. Specifically, participants evaluated the act of social exclusion as wrong using mostly fairness- and empathy-related explanations.

These findings support the claim that young children often give priority to fairness over group opinion or ingroup bias when the psychological welfare of another is at stake. Further, these findings provide an important caveat to the recent prevailing notion that children "prefer consensus" or "reject dissenters". These conclusions may well pertain to novel object labeling contexts, in which the child expects the consensus group to be informed about the name of an unfamiliar object. When evaluating a moral transgression, however, preschool children reject a consensus opinion condoning intergroup social exclusion.

Interestingly, the results from the novel object labeling context revealed that children were as likely to choose the consensus group's opinion as the dissenter's opinion. Children's explanations for their decisions revealed that they used clues about properties of the objects (e.g., shape, color, etc.) to determine their names. Only a small portion of participants mentioned the consensus testimony when justifying their decision. These findings suggest that children, at least in some contexts, sought a solution to the labeling task by taking into account their previous knowledge about words and objects.

Although the structure of a word is conventional, and therefore the role of the information provided by others is essential in learning new words, studies on language acquisition have also shown that children do not merely reproduce what they hear from adults. Based on their efforts to generalize from grammatical rules, children may construct their own labels, which often result in words that no adult would utter (e.g., "I have two foots") (see Slobin, 2001). Additionally, some other studies have also noted chance level responses for preschoolers' use of others' testimony. For example, Seston Schillaci and Kelemen (2014, (Study 1, weak condition) found that, when determining the function of novel objects, 3-4 year-olds did not defer to a consensus group's opinion over a dissenter's opinion when the testimony offered by both parties was equally plausible.

Notably, the race of the dissenter did not significantly influence children's decisions. Previous studies have shown that explicit references to race are not often a relevant variable for preschoolers when categorizing people (Enesco, Guerrero, Callejas, \& Solbes, 2008; Guerrero, Enesco, Lago, \& Rodríguez, 2010). Thus, it could be that our participants did not use the race of the dissenter when making decisions due to general lack of explicit racial biases found with young children. Research has revealed that young children have implicit racial biases, but this has been shown using implicit association tests, which are different from preference for testimony from an individual based on race. The more straightforward interpretation of these results is that children's inferences in this context were not influenced by informant racial group membership when only the race of the dissenter was manipulated.

Further, the finding that children endorsed the consensus option significantly more often in the labeling context than in the peer exclusion context, as we predicted, can also be interpreted in light of recent studies revealing that expertise in a domain reduces children's tendency to defer to group consensus (e.g., Seston Schillaci \& Kelemen, 2014). Related research on social exclusion has also shown that there are some circumstances in which exclusion is viewed as legitimate for conventional reasons (to make groups work well, or to promote group identity), while for other contexts exclusion is viewed as wrong for moral reasons (unfairness) (Killen \& Rutland, 2011). Thus, social exclusion is a complex social context. Children's explanations for their decisions in the present study revealed their empathy for the excluded child and interest in insuring fair treatment, rather than a focus on rules, prohibited activities, or majority opinion. In particular, the reasoning data support our conclusion that, rather than applying a specific local regulation ("We do not exclude in my classroom, that's the rule"), children interpreted the exclusion context in moral terms, appealing to broader ideas about fairness and empathy. Thus, supporting our broader prediction that use of consensus testimony is domain specific, this study demonstrated that children's reliance on the majority does not extend to the morally salient context of peer social exclusion.

In other social contexts, young children have been shown to defer to majority opinion, even when such an opinion directly contradicts their first-hand experience (Corriveau \& Harris, 2010; Haun \& Tomasello, 2011). For example, when preschoolers judged which animal image matched a model after exposure to an inaccurate peer consensus (Haun \& Tomasello, 2011), and judged which of a set of three lines was longest after exposure to an inaccurate adult consensus (Corriveau \& Harris, 2010), they conformed to the incorrect consensus opinion in approximately $20 \%$ to $37 \%$ of the trials. In the interracial social exclusion context explored in this study, only two children out of a sample of $90(2.2 \%$ of the sample) sided with the consensus (social exclusion is "okay") 
in both trials. Moreover, none of the children reasoned about a factor that could provide an acceptable justification for not inviting someone to a birthday party (i.e., they are not friends) or not playing with someone on the playground (i.e, she/he could fall down).

While conformity to group opinion serves important functions in the transmission of human culture (Haun \& Tomasello, 2011), in many circumstances it is not the right answer from a moral viewpoint, and dissenters play a crucial role in the development and progress of human society and culture. Researchers have emphasized that, in some cases, individuals dissent because they have moral convictions that prevent them from following and acting in line with group norms (e.g., Jetten \& Hornsey, 2014, p.465). As an example, throughout human history, individuals who dissented from laws and customs deemed unfair have been viewed as moral leaders (e.g., Martin Luther King, Mahatma Ghandi). Our conclusion is that use of consensus opinion is not a domain-general strategy; it depends not only on children's previous knowledge about a decision at hand, but also on the domain of knowledge in which children make judgments and decisions.

Thus, one of the most interesting findings from this study pertained to the different ways in which children approached and interpreted each decision-making context. In the peer exclusion scenarios, virtually all children interpreted the events as morally wrong, and over half of children's reasons pertained to fair treatment of others and empathy for the excluded child. By contrast, in the object labeling scenarios, children's decisions were split between agreement with the consensus and the dissenter, but their justifications converged on a common theme: properties of the object. Our experimental design, while ideal for testing the contextual specificity of children's reliance on consensus opinion, required that children's reasoning be measured after their decision had been made, which precluded a complete investigation of children's self-generated potential reasons for reaching one decision or another antecedent to their final election. Thus we emphasize that the reasoning reported here pertains to children's justifications for their decisions and therefore may not include every possible source of information that children may have considered. However, these findings indicate that children weighed very different sets of social criteria when evaluating peer social exclusion versus labeling a novel object.

Finally, previous research on social exclusion has shown that children develop in-group preferences, which are both positive and negative. The positive aspect is that group affiliation and group identity is necessary and positive for adaptation to society; group identity has important affiliative and affective benefits. Prejudice arises, however, when in-group preference turns into out-group dislike. This is not an automatic association but occurs when in-groups are threatened or insecure. These group processes are part of children's social -cognitive and social -emotional development (Killen \& Rutland, 2011). There is little evidence that these processes are an outcome of social consensus. In fact, quite early on in childhood children challenge group norms (Cooley \& Killen, 2015), resist stereotypic associations, and give priority to moral norms over group norms that promote negative outgroup attitudes (Abrams, Rutland, Pelletier \& Ferrell, 2009).

\section{Limitations, Future Directions and Conclusions}

Our results suggest several avenues for future research. First, the study focused on children's evaluation of one specific moral scenario. Future research could examine other morally-relevant social contexts and decisions, like the distribution of limited resources, in order to determine the influence of a consensus across a variety of salient social contexts in which moral considerations may conflict with group opinions.

A second direction for future research is the investigation of children's trust in the opinion of a social consensus regarding complex or ambiguous social contexts in which different perspectives may be taken. In a more social ambiguous context, children may deem the consensus opinion more helpful when making an inference or decision. The moral situations presented to participants in this study were relatively straightforward (a child has been explicitly and intentionally excluded). Therefore, it would be interesting to explore, for example, if young children would side with the opinion of a consensus in situations in which more than one choice is morally relevant or acceptable.

Third, this study (and most other related work in the field) presented testimony using adult informants. Future research could focus on other relevant characteristics of the individuals who make up the majority group and the dissenter. In research on epistemic authority, children's deference to the majority can also vary if it is formed by peers instead of adults. There are few studies with preschoolers where the testimony comes from a peer (Haun \& Tomasello, 2011; Walker \& Andrade, 1996) and almost none of these pertain to testimony about social contexts. Other domains of knowledge in which norms are debatable, such as social conventions, are also an interesting focus of inquiry. Young children acquire knowledge about conventions through personal experience, social interaction, and the testimony of others, but further investigation is necessary to assess the precise role of testimony and consensus in this and other domains.

Fourth, in the present research a dissenting opinion was always offered in contrast to the majority consensus testimony. This dissenting opinion is particularly relevant when moral issues are at stake. Future studies could weigh the strength of children's rejection of social exclusion when they face a majority opinion condoning the act with no dissenting opinion condemning it. The aforementioned studies on conformity in simple perceptual tasks (Corriveau \& Harris, 2010; Haun \& Tomasello, 2011) found that some preschoolers sided with the consensus when no dissenter was present. Other work has found that the role of the dissenter in social scenarios is related to the culture in which deference to the majori- 
ty is explored (Enesco, Sebastián-Enesco, Guerrero, Quan, \& Garijo, 2016). In a different line of results, some recent studies on other socio-conventional domains (i.e. alternative use of common objects) has shown that children are, on average, faithful to their own beliefs about existing conventions even when there is not a dissenter aligned with them (Guerrero, Cascado, Sausa, \& Enesco, 2017). Overall, the specific role of a dissenting opinion for children's judgments and reasoning presents a fruitful question for future research.

Fifth, for this study, the level of ethnic heterogeneity of children's schools was not directly controlled (although this level in general was very low -less than $20 \%$ ethnic minority children at each school). This is one potential limitation of the study, as it is well known that interethnic contact at school is a complex variable related to other meaningful experiences, like cross-group friendships or conflicts, that can promote or hinder positive social intergroup relations (e.g., Rutland, Cameron, Bennett, \& Ferrell, 2005, in Great Britain; McGlothlin \& Killen, 2005, in the U.S.). Future research could explore to what extent this factor (school ethnic heterogeneity) may affect children's responses to instances of social exclusion endorsed by an ethnic majority consensus group.

Finally, though this study was not designed to measure individual differences, our findings suggest that children do differ in their susceptibility to the influence of the group consensus. From an educational perspective, this is a particularly important aspect that, unfortunately, has not been explored systematically in this area of research. All children start the school years with implicit theories about their surrounding world, but it is likely that not all children are equally sensitive to the opinion of others. Some children may be extremely reluctant to change their own ideas, while others may be quickly prone to accept others' ideas, and most children likely fall between the two extremes. Research on children's use of consensus testimony has neglected individual

\section{References}

Abrams, D., Rutland, A., Pelletier, J., \& Ferrell, J. (2009). Children's group nous: Understanding and applying peer exclusion within and between groups. Child Development, 80, 224-243. doi:10.1111/j.14678624.2008.01256.x

Asch, S.E. (1956). Studies of independence and conformity: 1. A minority of one against a unanimous majority. Psychological Monographs, 70 (9, Whole No. 416)

Bond, R., \& Smith, P.B. (1996). Culture and conformity: A meta-analysis of studies using Asch's (1952b, 1956) line judgment task. Psychological Bulletin, 119, 111-137.

Chen, E. E, Corriveau, K.H., \& Harris, P.L. (2011). Children are sociologists. Anales de Psicología, 27, 625-630.

Chen, E. E., Corriveau, K.H., \& Harris, P.L. (2013). Children trust a consensus composed of outgroup members-but do not retain that trust. Child Development, 84, 269-282. doi: 10.1111/j.1467-8624.2012.01850.x

Cooley, S., \& Killen, M. (2015). Children's evaluations of resource allocation in the context of group norms. Developmental Psychology, 5, 554-563. doi: $10.1037 / \mathrm{a} 0038796$

Corriveau, K. H., Fusaro, M., \& Harris, P.L. (2009). Going with the flow: Preschoolers prefer non-dissenters as informants. Psychological Science, 20, 372-377. doi: 10.1111/j.1467-9280.2009.02291.x variability on this dimension, which seems to appear early in childhood. These differences may be related to the way that children approach both learning and knowledge acquisition and development, and also to how children behave in social scenarios such as bullying situations, where being a dissenter could have a personal cost.

This study demonstrates the context-specificity of young children's reliance on consensus opinion, and highlights the need for additional research on children's reasoning about the information that they receive from others. The vast majority of young children in this study agreed with the opinion of a single dissenter who stated that exclusion of a peer from a social activity on the basis of race was wrong, even when three other individuals condoned the action. Further, children reasoned about fairness and empathy for the excluded child, even when group considerations about fitting in could have been salient factors in their decision. By contrast, children were more likely to agree with the majority opinion when determining the name of a novel object. Taken together, these findings convey a broader message about young children's use of information provided by others. Rather than accepting all testimony, from as early as the preschool years young children are selective, weighing the information provided by others with their own moral judgments and appraisals in order to arrive at a decision.

Author Note: The study presented in this article was supported by the Ministerio de Economía y Competitividad of Spain (PSI201231477), awarded to Ileana Enesco. The study was also supported by a research grant to the first author from the Ministerio de Educación of Spain, "José Castillejo" (JC2011-0268).

Acknowledgments. We owe thanks to $\mathrm{M}^{\mathrm{a}}$ Sagrario Alba, Moussokoura Coulibaly, Alexandra M. Ion, Elena de la Llave, Nerea Muñoz, and Federico Pérez and for their collaboration in the materials for this research.

Corriveau K. H., \& Harris, P. L. (2010). Preschoolers (sometimes) defer to the majority in making simple perceptual judgments. Developmental Psychology, 46, 437-445. doi: 10.1037/a0017553

Dunham, Y., Baron, A. S., \& Banaji, M. R. (2006). From American city to Japanese village: A cross-cultural investigation of implicit race attitudes. Child Development, 77, 1268-1281.

Enesco, I., Guerrero, S., Callejas, C., \& Solbes, I. (2008). Intergroup attitudes and reasoning about social exclusion in majority and minority children in Spain. In S. Levy \& M. Killen (Eds.), Intergroup attitudes and relations in childhood through adulthood (pp. 105-125). New York: Oxford University Press.

Enesco I, Lago O, Rodríguez P., \& Guerrero S. (2011). 'We are the good guys but they are not bad'. In-group positivity and cognitive performance in preschoolers. British Journal Developmental Psychology. 29, 593611.

Enesco, I., Sebastián-Enesco, C., Guerrero, S., Quan, S., \& Garijo, S. (2016). What makes children defy majorities? The role of dissenters in Chinese and Spanish preschoolers' social judgments. Frontiers in Psychology, 7, 1695. doi:10.3389/fpsyg.2016.01695 
Einav, S., \& Robinson, E. J. (2010). Children's sensitivity to error magnitude when evaluating informants. Cognitive Development, 25, 218-232. doi:10.1016/j.cogdev.2010.04.002

Fitneva, S. A., \& Dunfield, K. A. (2010). Selective information seeking after a single encounter. Developmental Psychology, 46, 1380-1384. doi: $10.1037 / \mathrm{a} 0019818$

Fusaro, M., \& Harris, P. L. (2008). Children assess informant reliability using bystanders' non-verbal cues. Developmental Science, 11, 771-777.

Gopnik, A., \& Wellman, H. M. (2012). Reconstructing constructivism: Causal models, Bayesian learning mechanisms, and the theory theory. Psychological Bulletin, 138, 1085-1108. doi: 10.1037/ a0028044

Guerrero, S., Cascado, C., Sausa, M., \& Enesco, I. (2017). My teacher is wrong: Preschoolers' opposition to non-conventional statements. Manuscript accepted for publication in Early Childhood Research Quarterly.

Guerrero, S., Enesco, I., Lago, O., \& Rodríguez, P. (2010). Preschool children's understanding of racial cues in drawings and photographs. Cognitive Development, 25, 79-89. doi: 10.1016/j.cogdev.2009.07.001

Guerrero, S., Enesco, I., \& Pons, R. M. (Eds.) (2011). Social and Developmental Aspects of Prejudice during Childhood and Adolescence [Guest Editors, Monograph Issue]. Anales de Psicología, 27, (3).

Haun, D., \& Tomasello, M. (2011). Conformity to peer pressure in preschool children. Child Development, 82, 1759-1767. doi: 10.1111/j.14678624.2011.01666.x

Harris, P. L. (2012). Trusting what you're told: How children learn from others. Cambridge, MA: Belknap Press/Harvard University Press.

Jaswal, V. K. (2010). Believing what you're told: Young children's trust in unexpected testimony about the physical world. Cognitive Psychology, 61, 248-272. doi: 10.1016/j.cogpsych.2010.06.002

Jaswal, V. K., Carrington Croft, A., Setia, A. R., \& Cole, C. A. (2010). Young children have a specific, highly robust bias to trust testimony. Psychological Science, 21, 1541-1547. doi: 10.1177/0956797610383438

Jetten, J., \& Hornsey, M. (2014). Deviance and dissent in groups. Annual Review of Psychology, 65, 461-485. doi: 10.1146/annurev-psych-010213115151

Killen, M., \& Rutland, A. (2011). Children and exclusion: Morality, prejudice, and group identity. New York: Wiley/Blackwell Publishers.

Killen, M., \& Smetana, J.G. (2015). Origins and development of morality. In R.M. Lerner \& M. E. Lamb (Ed.), Handbook of child psychology and developmental science, Vol. 3, $7^{\text {th }}$ edition (pp. 701-749). NY: Wiley-Blackwell.

Killen, M., \& Stangor, C. (2001). Children's social reasoning about inclusion and exclusion in gender and race peer group contexts. Child Development, 72, 174-186.

Kinzler, K.D., Corriveau, K.H., \& Harris, P.L. (2011). Preschoolers' use of accent when deciding which informant to trust. Developmental Science, 14, 106-111.

Koenig, M. A. (2012). Beyond semantic accuracy: Preschoolers evaluate a speaker's reasons. Child Development, 83, 1051-1063. doi: 10.1111/j.1467-8624.2012.01742.x

Koenig, M. A., \& Harris, P. L. (2005). Preschoolers mistrust ignorant and inaccurate speakers. Child Development, 76, 1261-1277.

Levy, S.R., \& Killen, M. (Eds.). (2008). Intergroup attitudes and relations in childhood through adulthood. Oxford, England: Oxford University Press. Honorable Mention, Otto Klineberg Intercultural and International Relations Prize, from the Society for the Psychological Study of Social Issues (SPSSI)
McGlothlin, H., \& Killen, M. (2005). Children's perceptions of intergroup and intragroup similarity and the role of social experience. Applied Developmental Psychology, 26, 680-698. doi: 10.1016/j.appdev.2005.08.008

Mills, C. M. (2013). Knowing when to doubt: Developing a critical stance when learning from others. Developmental Psychology, 49, 404-418. doi: $10.1037 / \mathrm{a} 0029500$

Nucci, L. P. (2001). Education in the moral domain. New York, NY US: Cambridge University Press.

Nucci, L. P. (2002). The development of moral reasoning. In U. Goswami (Ed.), Blackwell handbook of childhood cognitive development. (pp. 303-325). Malden: Blackwell Publishing.

Piaget, J. (1932). The moral judgment of the child. New York: Free Press.

Piaget, J. (1954). The construction of the reality of the child. New York, NY: Basic Books.

Rutland, A., Cameron, L., Bennett, L., \& Ferrell, J. (2005). Interracial contact and racial constancy: A multi-site study of racial intergroup bias in 3-5 year old Anglo-British children. Journal of Applied Developmental Psychology, 26, 699-713.

Rutland, A., \& Killen, M. (2015). A developmental science approach to reducing prejudice and social exclusion: Intergroup processes, socialcognitive development, and moral reasoning. Social Issues and Policy Review, 9, 121-154.

Seston Schillaci, R., \& Kelemen, D. (2014). Children's conformity when acquiring novel conventions: The case of artifacts. Journal of Cognition and Development, 15, 569-583 doi: 10.1080/15248372.2013.784973

Shutts, K., Banaji, M. R., \& Spelke, E. S. (2010). Social categories guide young children's preferences for novel objects. Developmental Science, 13, 599-610.

Slobin, D. I. (2001). Form/function relations: How do children find out what they are? In M. Tomasello \& E. Bates (Eds.), Language development: The essential readings (pp. 267-289). Malden: Blackwell Publishing.

Smetana, J. G. (1985). Preschool children's conceptions of transgressions: The effects of varying moral and conventional domain-related attributes. Developmental Psychology, 21, 18-29. doi: 10.1037/00121649.21.1.18

Smetana, J.G., Jambon, M., \& Ball, C. (2014). The social domain approach to children's moral and social judgments. In M. Killen \& J.G. Smetana (Eds.), Handbook of Moral Development (pp. 23-45). New York: Psychology Press.

Theimer, C. E., Killen, M., \& Stangor, C. (2001). Young children's evaluations of exclusion in gender-stereotypic peer contexts. Developmental Psychology, 37, 18-27.

Turiel, E. (1983). The development of social knowledge: Morality and convention. Cambridge, England: Cambridge University Press.

Turiel, E. (2002). The culture of morality: Social development, context, and conflict. New York, NY: Cambridge University Press.

Turiel, E. (1998). The development of morality. In W. Damon \& N. Eisenberg, Handbook of Child Psychology, Vol. 3: Social, emotional, and personality development $\left(5^{\text {th }}\right.$ ed., pp. $\left.863-932\right)$. New York: Wiley.

Walker, M. B., \& Andrade, M. G. (1996). Conformity in the Asch task as a function of age. Journal of Social Psychology, 136, 367-372.

(Article received: 26-10-2015; revised: 04-01-2016; accepted: 08-02-2016) 